\title{
A HISTÓRICA SEGREGAÇÃO JURÍDICO-SOCIAL ENTRE "MADAMES" E "SATÃS": ANÁLISE CRIMINOLÓGICA ACERCA DA MARGINALIZAÇÃO DA CULTURA NEGRA NO BRASIL
}

Gabriela Galdino

Universidade Federal do Rio Grande do Norte

Email: gabggcosta@gmail.com

\section{RESUMO}

Frente à histórica e ainda crescente exclusão da população pobre no Brasil, o presente artigo busca apresentar uma análise criminológica acerca da marginalização das culturas periféricas do país, baseando-se, para isso, na figura exemplificativa de João Francisco dos Santos, que atendia pela alcunha Madame Satã, um dos símbolos da vida noturna do Rio de Janeiro na primeira metade do século XX. Destarte, por objetivar uma interpretação crítica sobre a essência dos fenômenos humanos, transcendendo os limites da aparência, utilizou-se o método fenomenológico de pesquisa, valendo-se de reflexões pautadas em doutrina, jurisprudência e legislação. Ao final, chegou-se à conclusão de que o sistema penal é limitado e submisso aos interesses de uma minoria dominante, de maneira que a criminalização dos excluídos assim como as expressões transgressoras destes - figura como fruto desse processo.

Palavras-chave: Análise criminológica. Cultura negra. Madame Satã. Sistema penal.

"Satã é mais um anjo que o inferno acolheu. A Lapa é um mundo que jamais ele esqueceu."

(Trecho de Samba-Enredo da Escola Lins Imperial) 


\section{INTRODUÇÃO}

Embora dono de uma história ainda juvenil, o Brasil carrega extensa e crescente trajetória de marginalização das minorias sociais e de suas expressões culturais. A população negra e pobre -herdeira de práticas, culturas e cores dos escravos libertos pela Lei Áurea de 1888 - vem sendo, historicamente, excluída, explorada e perseguida pelos setores mais elevados da sociedade.

Assim, a problemática deste estudo volta-se para a análise do modelo jurídico-penal aplicado no Rio de Janeiro do século XX e suas implicações no sistema segregacionista presente ,atualmente, nos morros cariocas. Para tanto, de maneira resumida,dada a complexidade da personagem, utiliza-se exemplificativamente a figura de Madame Satã, como representante emblemática dos estereótipos marginalizados.

Ademais, o objetivo geral desta pesquisa baseia-se não na romantização ou justificação do crime, longe disso,pauta-se na explanação da origem dacriminalidade edacriminalização, por meio da aproximação entre a criminologia e as manifestações das classes mais baixas, simbolizadas, aqui,essencialmente, por conhecidos fatos da vida deJoão Francisco dos Santos, que atendia pela alcunha Madame Satã, um dos símbolos da vida noturna do Rio de Janeiro na primeira metade do século XX.

Diante disso, foi dada margem para a elaboração de objetivos específicos, tais quais: apresentar o desenvolvimento do sistema jurídico-penal positivista e reformador do século XX; analisar o crescimento de uma cultura desviante, da qual Madame Satã é exemplo; inserir a personagem em discursos pertencentes a teorias criminológicas mundialmente estudadas; identificaro que mudou no perfil do transgressor do século passado e o que se mantém inalterado até hoje.

Por conseguinte, apresenta-se o samba, a capoeira, o rap e o funk como culturas transgressoras, que deram rosto e voz aos excluídos de distintas épocas. Nesse contexto, questionam-se os limites do direito penal e intenciona-se desvincular a personagem Madame Satã da maldade que, muitas vezes, lhe é associada, a fim de compreender por outra ótica as figuras marginais, sem que a elas seja atribuído um prévio e precipitado juízo de valor.

Para isso, fez-se necessária consulta bibliográfica, prioritariamente, em livros e manuais de direito penal e criminologia, além de reflexões acerca de dispositivos expressos no Código Penal de 1890 eno de 1940, que segue vigente. Vale ressaltar ainda, a utilização de artigos científicos e matérias retiradas da internet, destacando o estudo "Malandro quando morre vira samba: criminologias marginais de Madame Satã a Mano Brown”, de 
José Antônio Gerzon Linck, publicado no livro "Criminologia Cultural e Rock" (2011), fruto de um minicurso realizado na Universidade Federal do Rio Grande do Sul (UFRGS). Por fim, merece ser citado o filme "Madame Satã", de 2002, que, brilhantemente protagonizado pelo ator Lázaro Ramos, despertou a ideia de elaboração da presentepesquisa.

Sendo assim, é imprescindível posicionar-se frente a um tema atemporal, que acompanha sem trégua o desenvolvimento da sociedade. Logo, a pesquisa classifica-se como qualitativa - a qual permite a adoção de múltiplos procedimentos, técnicas e pressupostos - sustentada pelo método fenomenológico, que possibilita interpretações mais aprofundadas, além das aparências, buscando, assim, a essência dos fenômenos. Afinal, acredita-se que a realidade não é única, cabendo ao pesquisador analisar criticamente os aspectos que interferem no cotidiano e na evolução da sociedade.

\section{BREVE HISTÓRICO SOCIAL EJURÍDICO DO RIO DE JANEIRO DO SÉCULO XX}

No início do século XX, o Rio de Janeiro, então capital federal, viveu intensas e tumultuadas transformações urbanas, que jogaram à margem da sociedade boa parte da população local. A recente industrialização exigia a adaptação do perfil da mão de obra, ainda remanescente do fim da escravidão de 1888, que passou a compor uma extensa categoria de trabalhadores livres. Além disso, o crescimento populacional era incessante, embora a maior parte da população não tivesse direito a representação política, visto que a Constituição de 1891 excluía dos pleitos eleitorais bem mais da metade dos habitantes do Rio de Janeiro (mulheres, analfabetos, mendigos, entre outros), submetendo-os à vontade da minoria dominante.

$\mathrm{Na}$ intençãode recuperação da metrópole, ordenaram-se reformas na infraestrutura e investimentos na indústria hoteleira e de entretenimento, que só foram possíveis a partir da desapropriação em massa, compensadas por indenizações irrisórias, as quais fortaleceram a crise habitacional da camada mais pobre. Dessa maneira, enquanto os mais abastados povoaram a Zona Sul,a população mais pobre amontoou-se em bairros como Cidade Nova, Catumbi, Gamboa e Lapa.

Estes bairros, afastados do novo centro, tornaram-se depósitos de indivíduos indesejáveis, marginalizados, que não condiziam com a imagem de cidade ideal.A intenção era afastar ao máximo a população pobre, a fim de não macular o novo Rio de Janeiro da 
belle époque, exclusivo para a elite carioca.Contudo, as diversas reformas estruturais não atingiram a questão populacional e social, de forma que a camada de desempregados e trabalhadores informais aumentava a cada ano, agravando a inevitável disparidade entre o centro moderno e civilizado e a periferia atrasada e grosseira.

Frente a isso, ganhou força um ideal jurídico-penal de negação de toda a cultura divergente dos interesses da elite carioca, surgiua necessidade de não apenas afastar geograficamente aquilo que destoava da renovada identidade do Rio de Janeiro, mas também de proibir e reprimir o que ameaçava essa nova imagem.

\section{CRIMINALIZAÇÃO DA CULTURA NEGRA}

Fruto do período histórico que legitimou o discurso jurídico-penal de exclusão daqueles que não preenchiam os requisitos necessários para compor a nova face do Rio de Janeiro, ganhou visibilidade o lendário João Francisco dos Santos, conhecido como Madame Satã. Este - negro, pobre, analfabeto, morador do bairro da Lapa, transformista e homossexual - encontrou na vida transgressora a forma de resistir à marginalização. Para tanto, envolveu-se em conflitos com a polícia e foi detido por desacato à autoridade, muitas vezes em resposta a agressões que tinham como alvo prostitutas, mendigos, homossexuais e negros.

Exímio capoeirista, Madame Satã contrariava a legislação da época, permanecendo constantemente sob a mira da perseguição policial. Afinal, com o objetivo de controlar e desarticular a cultura negra do centro do Rio, o Código Penal de 1890 criminalizava a capoeira nos seguintes termos:

Art. 402. Fazer nas ruas e praças públicas exercício de agilidade e destreza corporal conhecida pela denominação Capoeiragem: andar em carreiras, com armas ou instrumentos capazes de produzir lesão corporal, provocando tumulto ou desordens, ameaçando pessoa certa ou incerta, ou incutindo temor de algum mal.

Pena - de prisão celular por dois a seis meses.

Parágrafo único. É considerado circunstância agravante pertencer o capoeira a alguma banda ou malta. Aos chefes ou cabeças, se imporá a pena em dobro ${ }^{1}$.

\footnotetext{
${ }^{1}$ BRASIL. Decreto-Lei 847, de 11 de outubro de 1890. Código Penal. Sala das sessões do Governo Provisório, $2^{\circ}$ da Republica.
} 
Dessa maneira, a criminalização dos capoeiristas foi mantida até a promulgação do Código Penal de 1940, que embora tenha abolido o tipo penal, não foi capaz de extinguir a rotulação negativa da prática, ainda depreciada por sua origem escravocrata de matriz negra. Somente décadas depois, iniciaram-se estudos no sentido de difundir a capoeira como arte e elemento da cultura nacional.

João Francisco dos Santos destacou-se também por sua participação assídua nos carnavais cariocas. Notório transformista, recebeu o apelido de Madame Satã ao desfilarcom a fantasia de mesmo nome -, no bloco de rua "Caçadores de Veados". Todavia, por mais que hoje o samba represente mundialmente um dos maiores símbolos do Brasil, os carnavais de Madame Satã ainda eram associados às práticas culturais dos negros e a tentativa de manutenção da cultura afrodescendente no Rio de Janeiro, perante a proibição do candomblé.

Logo, enquanto a classe média fazia festas em clubes fechados, as camadas mais baixas organizavam-se em blocos de rua, que reuniam tradições nordestinas e elementos da cultura africana, entoados pelo samba. Afrontando os valores sociais da época, homens homossexuais ou não - ornados de plumas e lantejoulas, orgulhosamente desfilavam pelas ruas cariocas, atraindo uma multidão de foliões.

Assim, construiu-se a personagem Madame Satã, detentora de múltiplas identidades - o capoeirista, perseguido pela policia; o transformista homossexual, que adotava filhos de prostitutas, violando as normas sociais; o negro, pobre, nordestino, morador do Rio de Janeiro - todas elas transgressoras do seletivo discurso jurídico-penal da época.

\section{A BASE DA TRANSGRESSÃO DE MADAME SATÃ}

O sistema jurídico seletivo - aplicado no século XX, com a justificativa de solucionar um problema social não compatível com as reformas da época, e utilizado, hoje, para disciplinar e controlar a população mais pobre - é responsável pelo surgimento de figuras transgressoras tanto quanto por sua criminalização. Afinal, a violação das normas, muitas vezes, advém das proibições impostas por um modelo jurídico-social excludente.

Nessa ótica e em referência à personagem foco deste estudo, Madame Satã, assim como incontáveis anônimos brasileiros, figurava como resultado da marginalização de elementos culturais e representativos de grupos excluídos e submissos aos detentores dos processos normativos. Dessa forma, em um ciclo preocupante, o sistema excludente 
historicamente gera indivíduos transgressores das normas que lhe são impostas. A fim de eliminar esses agentes, taxados de criminosos e perigosos para a sociedade, o legislativo, amparado pelos demais poderes, elabora normas cada vez mais restritivas e criminalizadoras das camadas já excessivamente excluídas da sociedade. A inevitável resposta é o aumento de transgressores, recomeçando uma sequência que não possui fim.

Inserido nesse contexto, João Francisco dos Santos, a Madame Satã, buscava burlar as regras sociais e jurídicas de sua época. Estelionatário, cafetão e garoto de programa, rejeitava as normas que lhe eram impostas, construindosuas próprias regras e sua própria ética, com a finalidade de driblar a vida, que lhe destinou uma sociedade desigual e sem chances de ascensão.

Assim, homossexual, negro, nordestino no Sudeste do século XX, possuía todos os requisitos para se tornar mais um miserável, mas negou-se às normas externas, procurando maneiras, lícitas ou não, de fugir da realidade social. Desenvolveu seu próprio senso de justiça, diante da inércia do poder público frente aos interesses de membros das classes mais baixas, valendo-se, muitas vezes, de condutas criminosas para defender aquilo que encarava como justo.

Seguindo essa perspectiva, José Antonio Gerzon Linck descreve:

O contexto social é o contraste onde Madame Satã trabalha seus regimes de visibilidade, transitando por escalas que transcendem o visível/invisível: o trabalho de performance não é a busca da visibilidade ou da invisibilidade, mas o deslocar-se sempre entre as inúmeras nuances dos regimes de visibilidade. (LINCK, 2014, Não Paginado)

Vale ressaltar ainda o trecho do filme "Madame Satã" (2002) que retrata um dos momentos nos quais a personagem foi presa, sendo atribuída a ela a classificação de “criminoso costumário, desocupado, sínico e dissimulado por índole". Atenta-se para a subjetividade da adjetivação: a ideia de "índole criminosa", associando delinquência a patologia, como faz a criminologia positivista; bem como para a condição de "desocupado", esta não por mera aversão ao "serviço", mas por intolerância ao "patrão", que remetia à exploração oriunda dos feitores e senhores de escravos.

Afinal, no século XX, em mais um exemplo de criminalização da pobreza, ao invés de um problema social, o desemprego era uma questão penal. Para evitar conflito com a polícia e prisões arbitrárias, o pobre era obrigado a sujeitar-se a trabalhos mal remunerados, subalternos e humilhantes. Madame Satã negou-se, optando por maneiras alternativas de garantir a sobrevivência. 


\section{ETIQUETAMENTO SOCIAL}

Como visto, boa parte da população brasileirarecebeu uma forte e negativa carga social, que culminou na criminalização de seus atos e culturas. Nesse contexto, a marginalização das classes inferiores foi abordada pela "teoria do etiquetamento" (labelling approach).

Esta surgiu nos Estados Unidos da década de 1960, sendo influenciada pelo "interacionismo simbólico" - corrente sociológica que identifica a realidade humana não como feita de fatos, mas pautada na interpretação que as pessoas coletivamente destinam a estes, ou seja, de acordo com essa teoria, determinada conduta só será criminalizada se os mecanismos de controle social a classificarem como criminosa.

Logo, fugindo da dogmática penalista, crimes não são somente as violações injustificadas da lei penal, mas as condutas recriminadas e perseguidas pela sociedade e por seus órgãos punitivos. Frente a isso, o processo de etiquetamento pode ser dividido em dois momentos: o primeiro é a criação e imposição de normas, o segundo é a aplicação destas. Segundo Anitua (2008, p.592) "Em ambos (os momentos) selecionam-se comportamentos em abstrato e pessoas em concreto para impor-lhes etiquetas que implicarão uma recusa mais geral, além de configurar uma 'carreira delinquencial"”.

Sendo assim, a classificação de um criminoso não tem relação apenas com a ação por ele cometida, não se trata somente de uma conduta proibida praticada por alguém imputável (modelo dogmático), nem de um ato ilegal realizado poragente antissocial (modelo etiológico).Mais do que isso, é a analise interpretativa da gravidade da conduta, somada à figura de quem a cometeu, que fornecerá um resultado acerca da criminalização ou não de tal comportamento. Por esse motivo, centenas de atos presumidamente criminalizáveis nem sequer chegam a ser investigados, devido à posição social elevada dos agentes que os cometem.

Por outro lado, em oposição ao eufemismo com que são tratadas as infrações cometidas pela elite brasileira, as comunidades pobres, de maioria negra, sobrevivem em um infinito estado de suspeição, rotuladas diariamente de figuras desviantes e criminosas, obrigadas a provar constantemente sua inocência e honestidade. Trata-se do mesmo ciclo histórico que criminalizava a capoeira e o samba de Madame Satã, na década de 1930, e, hoje, marginaliza o funk e o rap dos morros cariocas. 
Corroborando essa ideia, Linck disserta:

\begin{abstract}
Madame Satã referindo-se o tempo inteiro à minha pessoa (e portanto negando o estereótipo genérico de homossexual, pobre ou ladrão), Bezerra da Silva lembrando que somos crioulosdo morro, mas ninguém roubou nada, Mano Brown ressaltando a indiferença por gente carente que se tem e o Rap da Felicidade entoado por Cidinho explicitando que só quer poder se orgulhar são alguns dos inúmeros exemplos fornecidos pela musica do permanente estado de suspeição a que os pretos tão pobres e os pobres tão pretos sempre foram vitimados no país. A estética malandra é a inversão e, portanto, representa verdadeira aversão ao "exige-se boa aparência" nos nossos classificados de emprego.(LINCK, 2011, P. 29 -30)
\end{abstract}

Inegavelmente, a criminalização codificada da pobreza perdura por décadas, de maneira que, hoje, apesar de tipificações abstratas, como a do delito da "capoeiragem", terem sido retirados do código, substitutos à altura seguem vigentes no sistema penal atual.É o caso do art. 176 do Código Penal ${ }^{2}$ brasileiro,cujo texto determina ser passível de detenção aquele que "tomar refeição em restaurante, alojar-se em hotel ou utilizar-se de meio de transporte sem dispor de recursos para efetuar pagamento".

O citado dispositivo, visivelmente, não tem o objetivo de criminalizar o dano ao patrimônio alheio ou a conduta imoral de não pagar pelo que foi consumido - visto que se o agente possuía recursos, mas optou por não efetuar o pagamento, o ilícito é apenas civil, livre da esfera penal. Logo, verifica-se que o tipo busca exclusivamente proibir o pobre de beneficiar-se de sua pobreza, trata-se de uma reafirmação da necessidade histórica de controle e depreciação das classes mais baixas.

Por conseguinte, a "teoria do etiquetamento" desconstruiu a ideia de que a função do direito penal é proteger a população de pessoas essencialmente ruins, por meio da distinção maniqueísta de sociedade como "bem" e criminoso como o "mal" que a macula. Pelo contrário, a ideologia que propõe o etiquetamento social revelou um tipo habitual de criminoso, pautado em ideais mantenedores da desigualdade social.

\title{
6 TEORIA DO CONFLITO E CRIMINOLOGIA CRÍTICA
}

Embora a perspectiva do etiquetamento tenha contribuído para a formação de uma criminologia crítica, não foi capaz de romper, por si só, com a criminologia liberal. Nesse

\footnotetext{
2 BRASIL. Decreto-Lei 2.848, de 07 de dezembro de 1940. Código Penal. Diário Oficial da União, Rio de Janeiro, 31 dez. 1940.
} 
sentido, Zaffaroni (1998, p.60 et seq.) argumenta que foi uma teoria de médio alcance, insuficiente, e que, portanto, deveria ser completada, mas nunca desqualificada.

Sendo assim, o que os criminólogos da labelling approach, ou "teoria do etiquetamento", definiam como sua verificação final representou o ponto de partida para os teóricos de novas criminologias, que buscaram adentrar a construção normativa da criminalidade, a fim de decifrar quais eram os poderes capazes de rotular determinadas condutas como desviadas, separando os grupos detentores do poder etiquetador, daqueles marginalizados.

Nessa ótica, a teoria do conflito foi aperfeiçoada por pensadores marxistas e não marxistas, que estudaram determinadas minorias étnicas e rebeliões juvenis, além de outras condutas socialmente desviadas, proibidas nos Estados Unidos e na Europa, rompendo com a ideia de coletividade singular. A sociedade era plural e antagônica, com diversos grupos em constante disputa por espaço e poder político.

No Brasil, Madame Satã inseria na história o seu mais conhecido delito, a morte do sambista Geraldo Pereira com um único golpe. Embora até hoje se questione a veracidade do fato, existindo, inclusive, versões de que a falácia foi criada pelo próprio João Francisco, o que se sabe é que eleveementemente vangloriava-se do crime cometido em um bar da Lapa, longe dos olhos da elite carioca.

Valendo-se do caráter simbólico da personagem para o estudo da teoria então exposta, admite-se que a sociedade é essencialmente conflituosa, dessa forma a coerção faz com que os sistemas sociais sejam mantidos coesos. A concepção de que "toda sociedade é baseada na coerção de alguns de seus membros por outros" (DAHRENDORF apud SHECAIRA, 2004, p. 137)e que o conflito é resultado das lutas pelo poder, a partir de relações formadas entre grupos distintos, oferece margem para a discussão do crime nessa sociedade. Perante essa perspectiva, é possível compreender a necessidade de Madame Satã de fazer-se conhecido por uma ação criminosa e violenta, como o homicídio do famoso sambista, visto que jamais receberia visibilidade, por vias legais, em uma sociedade que o rotulara invisível por natureza.

Adiante, as teorias conflituais prepararam o espaço para as análises críticas, partindo da ideiade um conflito de luta de classes elaborado perante os modos de produção e infraestrutura da sociedade capitalista. Rompe-se com o pensamento liberal, que não contesta os processos discriminatórios determinantes das condutas desviadas e admitem-se como necessários os conflitos sociais para manutenção da sociedade coesa. 
Logo, destaca-se uma criminologia que apoia a questão criminal e a reação social em uma perspectiva histórico-analítica. O fenômeno criminal como produto do confronto de classes antagônicas, no qual uma explora as demais, sendo responsável pela seleção dos fatos socialmente desviados, está atrelado ao capitalismo contemporâneo e suas estruturas legais.Frente a isso, cabe ressaltar a ideia de que o estudo do crime pauta-se na reprodução das condições de produção (separação do trabalho e meios de produção) por superestruturas de controle social (instituições jurídicas e políticas), as quais definem práticas contrárias às condições de produção, onde se encontra o crime (SANTOS, 1981).

Aquicabe relembrar a afronta de Madame Satã às ordens da organização social, ao afirmarque havia nascido para ser "malandro". E como "bom malandro", rejeitou qualquer submissão a regimes externos e a disciplina do trabalho, escolhendo viver por si, da maneira que julgava decente, longe do jugo alheio. Para tanto, fugindo dos limites que a sociedade lhe impunha, taxado de "vagabundo", "desocupado", "preguiçoso" e, por isso, detentor do estereótipo de delinquente, era alvo constante de perseguições policiais.

Partindo desse exemplo, verifica-se o estudo das causas do desvio criminal sendo deslocado e associado aos mecanismos sociais e institucionais, que constituem a realidade social do desvio, e aos mecanismos criadores das definições de desvio e criminalidade(BARATTA, 1999).Em uma ótica crítica, o crime deixa de ser uma realidade ontológica, passando a ser um rótulo atribuído a certas pessoas mediante dois requisitos: seleção de bens protegidos penalmente e a seleção de determinados indivíduos que serão etiquetados, entre vários outros que cometem as mesmas infrações criminalizáveis.

As proposições críticas negam o mito do direito penal igualitário, pautado na proteção de todos os cidadãos. Ao contrário, os teóricos passam a levantar premissas de que: as leis não são iguais para todos, assim como é desigual o status de criminoso; o direito não defende os bens essenciais a todos os cidadãos; e o direito penal é desproporcional por excelência.

\section{HERDEIROS DE MADAME SATÃ}

A mutabilidade do espaço urbano transformou a paisagem, a cultura e os valores sociais. Dessa forma, os ideais de Madame Satã não são os mesmos dos jovens de hoje, contudo, a incessante tentativa de manter-se dentro das exigências de uma sociedade 
desigual segue a mesma de outrora, ainda que, para isso, seja necessário valer-se de condutas ilícitas.

Nesse contexto, é um discurso desatualizado e demasiadamente romantizado aquele que se apega ao pensamento de que os criminosos pobres do Brasil cometem apenas delitos de ordem essencialmente famélica. Longe disso, os "herdeiros" mais recentes de Madame Satã nasceram em plena sociedade de consumo, que atrela o poder de compra à própria identidade do indivíduo. Os morros cariocas reúnem multidões ao som do moderno "funk ostentação", e este dita o que é necessário para ser aceito socialmente.

Assim como a figura transgressora de Madame Satã, violando aquilo que acreditava ser injusto, o rap e o funkrepresentamo discursoatual que empodera e dá voz às comunidades periféricas, afrontando o segregacionismo do sistema. Além disso, mais que o "funk ostentação" - que retrata um status a ser almejado e seguido pelos jovens - o "funk proibidão" relata o cotidiano de crimes e violência vivenciado pela população excluída.

Semelhante ao samba, ao candomblé e à capoeira no século passado, as tentativas de criminalização do funk e do rapperduram da década de 1990 até hoje. Trata-se de mais um esforço para controlar e calar as vozes dos mais pobres. Em 2015, o "funk proibidão" protagonizou a decisão,proferida pelo juiz de Direito Marcos Augusto Ramos Peixoto, da $37^{\mathrm{a}}$ vara Criminal do Rio de Janeiro, que acertadamente rejeitou a denuncia de apologia ao crime, feita pelo Ministério Público do estado, contra um cantor desse estilo musical.

No referido processo, o magistrado lembrou o histórico de censura vivido pelo Brasil e discorreu acerca da criminalização do movimento artístico e social representado pelo funk carioca:

\footnotetext{
Trata-se, enfim, de uma tentativa de 'pacificação' do discurso dos excluídos depois de terem invadidos e controlados seus territórios por Unidades de Polícias Pacificadoras (UPPs), pretende-se o controle de seus corações e mentes, já que 'o funk proibidão representa a redenção de um 'lugar de fala' que deveria permanecer no silêncio'.Tem por fundamento e objetivo esta demanda criminal, assim, o cerceamento à liberdade de expressão do outro, do diferente, daquele que nunca teve voz e que é bem visto desde que permaneça calado (e, porque não dizer, obediente) ${ }^{3}$.
}

Corroborando a inteligente e bem fundamentada decisão, admite-se que o carnaval de Madame Satã difere muito dos bailes cariocas, contudo, apresenta também diversas características em comum, sendo ambas as épocas - cada qual com seus representantes -

\footnotetext{
${ }^{3}$ TJRJ. 37 ${ }^{\mathrm{a}}$ VARA CRIMINAL DA COMARCA DA CAPITAL. Processo $\mathrm{n}^{0}$ 0002438-06.2014.8.19.0001. Arquivado em definitivo - maço n ${ }^{\circ}$ 2071, em 21 de outubro de 2015.
} 
fundamentais para a desconstrução ideológica do discurso jurídico-penal excludente e para dar visibilidade e representatividade àqueles que são historicamente ignorados.

\section{CONSIDERAÇÕES FINAIS}

Tomando por base o que vem sendo tratado neste estudo, admite-se queo sistema penal vigente, sufocado majoritariamente por crimes patrimoniais, atende às classes médias e baixas no sentido de reaver - de maneira falha e insuficiente-direitos que são irrelevantes aos membros das classes mais altas, paraos quais pequenos furtos e roubos pouco interferem no patrimônio. Esse é o modelo penal sob sua face deficitária, que julga "o pobre que roubou o pobre”, mas não dá um resultado plenamente satisfatório a este, tampouco ressocializa aquele. Trata-se da manutenção de uma falsa ideia de que, é necessário controlar a violência individual, quando, por outro lado, pouco se questiona a violência estrutural.

Adotando uma segunda face, tem-se um direito penal funcionandoa serviço da pequena parcela detentora de poder político, jurídico e econômico, sendo por ela utilizado como administrador da criminalidade. O processo de elaboração e aplicação das leis é orientado pela ideologia dominante, e tem como resultado o fenômeno do crime. Logo, a justiça penalnão dispõe de quaisquer meios para evitar e combater a criminalidade, servindo apenas como instrumento para selecionar, nas classes trabalhadoras, sua clientela habitual.

No século XX, Madame Satã mostrou-se como resultado e expressão de resistência a esse sistema jurídico-penal, quebuscava controlar e segregar a população pobre e, essencialmente, negra do Rio de Janeiro. Para tanto, era transgressor assumido do discurso moralizante de uma elite que criminalizava todas as práticas culturais cuja disseminação representasse ameaça ao seu poder de opressão sobre os excluídos.

Dessa forma, a propagação dos discursos criminalizantes dos negros, pobres, moradores dos bairros periféricos do século XX, são utilizados hoje para marginalizar os herdeiros sociais, culturais e étnicos de Madame Satã. O preconceito e racismo estatais recriminam não mais o capoeirista da Lapa, mas o funkeiroe o rapper do morro carioca.

Essas figuras que, cada uma ao seu tempo, representam perturbação à ordem, resistem à ideologia criminalizante positivista. São personagens, anônimos ou não, que veem na transgressão a melhor forma de existir e, mais do que isso, ganham visibilidade e 
denunciam diariamente o descaso com que, constrangedoramente, é tratado o submundo de uma sociedade excludente.

\section{REFERÊNCIAS}

ANITUA, Gabriel Ignacio. Histórias dos pensamentos criminológicos. Rio de Janeiro: Revan, 2008.

BARATTA, Alessandro. Criminologia crítica e crítica do direito penal. 3 ed. Rio de Janeiro: Revan, 2002.

BRASIL. Decreto-Lei 2.848, de 07 de dezembro de 1940. Código Penal. Diário Oficial da União, Rio de Janeiro, 31 dez. 1940.

BRASIL. Decreto-Lei 847, de 11 de outubro de 1890. Código Penal. Sala das sessões do Governo Provisório, $2^{\circ}$ da Republica.

DAHRENDORF, Ralf. O conflito social moderno: um ensaio sobre a política da liberdade. Apud SHECAIRA, Sérgio Salomão. Criminologia. São Paulo: RT, 2004.

LINCK, José Antônio Gerzon. Malandro quando morre vira samba: criminologias marginais de Madame Satã a Mano Brown.In. CARVALHO, Salo et al. (Org).

Criminologia cultural e rock. Rio de Janeiro: Lumen Juris, 2011. Criminologia e transgressão: um laço entre movimentos culturais contemporâneos. In. Programa de pós-graduação em ciências criminais da Faculdade de Direito, PUCRS. Porto Alegre, 2014.

MADAME Satã. Direção Karim Ainouz. Roteiro Karim Ainouz; Marcelo Gomes e Sérgio Machado. País/Ano de Produção: Brasil / França, 2002. Duração: 105 minutos. Gênero: Drama biográfico. DVD.

SANTOS, Juarez Cirino dos. A criminologia radical. Rio de Janeiro: Forense, 1981. 
TJRJ. 37 ${ }^{\text {a }}$ VARA CRIMINAL DA COMARCA DA CAPITAL. Processo $\mathbf{n}^{\circ}$ 0002438-

06.2014.8.19.0001. Arquivado em definitivo - maço $n^{\circ} 2071$, em 21 de outubro de 2015.

ZAFFARONI, Eugenio Raúl. Criminologia: aproximación desde um margen. Bogotá:

Temis, 1998.

THE HISTORICAL LEGAL AND SOCIAL SEGREGATION BETWEEN

"MADAMES" AND "SATÃS": CRIMINOLOGICAL ANALYSIS ABOUT THE

MARGINALIZATION OF BLACK CULTURE IN BRAZIL

\begin{abstract}
Opposite the historic and still growing exclusion of the poor population in Brazil, this article seeks to present a criminological analysis about the marginalization of peripheral cultures of the country, relying, for that, in the illustrative figure of João Francisco dos Santos, who went by the nickname Madame Satã, one of the symbols of Rio de Janeiro nightlife in the first half of the 20th century. Thus, aim for a critical interpretation of the essence of the human phenomena, transcending the boundaries of appearance, it was used the phenomenological method of research, taking advantage of guided reflections in doctrine, jurisprudence and legislation. In the end, it was concluded that the penal system is limited and submissive to the interests of a dominant minority, so that the criminalization of the excluded - as transgressive expressions - figure as a result of this process.
\end{abstract}

Keywords: Criminological analysis. Black culture. Madame Satã. Penal system. 